\title{
Don Juan y las formas de representación simbólica de la muerte en el siglo XVII
}

\section{Don Juan and the Forms of Symbolic Representation of Death in the Seventeenth Century}

\author{
Leonarda Rivera \\ Universidad Nacional Autónoma de México \\ Facultad de Filosofía y Letras \\ leonardarivera@filos.unam.mx \\ orcid.org/oooo-0002-1301-4829
}

Resumen: Desde sus orígenes en el teatro del Siglo de Oro, don Juan ha sido visto como "un símbolo del placer carnal". El don Juan del siglo XviI es una máscara de la fiesta barroca, donde el sexo y la muerte aparecen entrelazados. Este artículo analiza la relación entre el tema de la muerte y el sexo como pilares de la historia de don Juan, como dos caras de la misma moneda: El burlador de Sevilla encarna el instinto sexual y el Convidado de piedra, la muerte.

Palabras clave: Culto a la Muerte, barroco, Convidado de Piedra, don Juan, voluptas carnis

Abstract: $\quad$ Since its origins in the Theater of the Golden Age, Don Juan has been seen as "a symbol of carnal pleasure". The seventeenth-century Don Juan seems to be a symbol of the baroque festival, where sex and death appear interwined. This paper analyzes the relationship between sexuality and Death as pillars in don Juan's story. Both embody two faces of the same coin: The Trickster of Seville embodies the image of sexual instinct and The Stone Guest "the Death".

Keywords: $\quad$ Cult of Death, Baroque, The Stone Guest, don Juan, voluptas carnis

Recibido: $\quad 26$ de mayo de 2020

Aceptado: $\quad 5$ de noviembre de 2020 
...que se domaría la carne si se pensase qual sería después de la muerte

Juan de Dueñas, Espejo del pecador, 1553

Cuando a finales del siglo xix en Así habló Zaratustra (Also sprach Zarathustra, 1883), Friedrich Nietzsche escribe "permaneced fieles a la Tierra /bleibt der Erde treu" (2009: 43), en realidad no estaba haciendo otra cosa que reafirmar la belleza que entraña lo terrenal, esa belleza imperfecta y efímera que en otro tiempo había sido condenada por la filosofía platónica. El filósofo alemán se arrodilla ante la belleza que entraña un mundo sin Dios. ${ }^{1}$

Pero antes de Nietzsche, en la tradición occidental, en el umbral de lo que conocemos como Modernidad, el don Juan barroco también había gritado a su manera: "Permaneced fieles a la Tierra". Y es que el don Juan que irrumpe en los teatros de los Siglos de Oro no solo constituye "la respuesta más violenta contra el culto a la muerte instaurado victoriosamente entre los siglos XVI y XVII" (Macchia 1998: 13), ${ }^{2}$ sino que es también la imagen de la celebración de la vida en su sentido más básico: el instinto sexual. 3

1 La sentencia completa que encontramos en Así habló Zaratustra dice: “¡Yo os conjuro, hermanos míos, permaneced fieles a la Tierra y no creáis a quienes os hablan de esperanzas sobreterrenales! Son envenenadores, lo sepan o no. Son despreciadores de la vida, son moribundos y están, ellos también, envenenados, la tierra está cansada de ellos: ¡ojalá desaparezcan!” [¡Ich beschwöre euch, meine Brüder, bleibt der Erde treu und glaubt Denen nicht, welche euch von überirdischen Hoffnungen reden! Giftmischer sind es, ob sie es wissen oder nicht] (F. Nietzsche, Also sprach Zarathustra. [Bd. 1]. Chemnitz, 1883).

2 Existe una extraña relación entre las epidemias que cebaron los reinos europeos de los siglos XV y XVI, y los registros que se tienen de las orgías. Hay estudios que indican que después de una oleada de muerte y desesperación, los habitantes de algunas ciudades europeas, durante los carnavales posteriores a las pestes, celebraron ruidosas orgías en diferentes puntos de las ciudades. Esto era más común en las ciudades medievales.

Véase Carla Jouan Dias Angelo de Souza, "Muerte y representación en la Edad Media: consideraciones sobre la imagen, la iconografía de la muerte y la influencia de la Peste Negra en el surgimiento de los temas macabros", De Medio Aevo, 12, 2018: 239-258.

3 Es raro que, en El burlador de Sevilla, Catalinón llame a don Juan "Langosta de las mujeres” (II, v 436), pues, como señala Aurora Egido (1988), en Sevilla los prostíbulos de la época se encontraban en la calle de las Sierpes. Don Juan es la serpiente que se enreda en el cuerpo de sus víctimas. Cabe señalar también que, en la versión de Tirso de Molina, sobre todo en los diálogos con la campesina y la pescadora, tienen un sentido sexual explícito: "Parecéis caballo griego / que el mar a mis pies desagua, / pues venís formado de agua, / y estáis preñado de fuego” (I, vv. 613-616). 
Hay que subrayar que este don Juan, sin importar si salió de la pluma de Tirso de Molina o de Andrés de Claramonte, 4 "no solo simboliza el triunfo del cuerpo sobre el alma, sino también la primacía de la sensualidad sobre lo espiritual" (Méndez 2000: 131). Don Juan es un personaje que solo podía nacer en una cultura tan religiosa y obsesionada con la muerte como fue la sociedad española de la Contrarreforma. Fernando de la Flor nos ha enseñado cómo en el siglo XVII, mientras Descartes descubría, casi de manera religiosa, la autonomía del yo "que piensa por sí mismo", y que estará en la base de la ciencia moderna, los intelectuales del barroco hispano, así como el pueblo en general, vivían obsesionados por la vanidad de todo y por la fugacidad de la vida ( $c f$. 2002: 71-73). Y es que la muerte parece ser la gran protagonista del barroco español, y junto a ella, el sentimiento de la nada y el fracaso de toda empresa humana en la Tierra: "La calavera aparece representada obsesivamente en todos los registros de la época” (De la Flor 2002: 71).

En sus estudios sobre la cultura del barroco, José Antonio Maravall también ha mostrado que la conciencia de finitud y el sentimiento de la nada aparecen mezcladas, casi confundidas, con la conciencia de crisis de la época: "la conciencia social de crisis que pesa sobre los hombres en la primera mitad del siglo XVII suscita una visión del mundo en la que halla expresión el desorden bajo el que las mentes de la época se sienten abnegadas. Son hombres tristes, como alguna vez los llamó Lucien Febvre" (Maravall 1975: 309). La cultura del barroco es una cultura de la crisis. Aquellos hombres que se habían sentido casi semidioses en el Renacimiento de pronto despertaron en los infiernos del mundo barroco. Tras los descubrimientos y avances que supuso el Renacimiento, sobre todo el protagonismo que adquirió el hombre en la esfera de la creación, en los siglos siguientes aparece la conciencia del pecado. La figura misma del hombre renacentista de pronto formará parte de la población que estará bajo sospecha. Por otro lado, aparecen una serie de cambios, convulsiones, que ocurren en un periodo breve. Para el hombre medio, este giro tan abrupto generó un sentimiento de pérdida, de extrañeza, pero, sobre todo, agravó su conciencia de finitud. A esto hay que agregar, en el

4 El filólogo Alfredo Rodríguez López-Vázquez, editor de El burlador de Sevilla para la editorial Cátedra, es uno de los más fieles defensores de que esta obra es de Andrés de Claramonte y no de Tirso de Molina. Véase "Introducción" a El burlador de Sevilla, Cátedra, 2013. Así como el texto "El burlador de Sevilla ¿Tirso o Claramonte?”, de Alfredo Rodríguez López-Vázquez y Luis Vázquez, en Hitos del teatro clásico, 46o-476. 
contexto de España, "la aparición de las cuatro grandes pestes, cuyas pérdidas por algunos historiadores han sido calculadas en tan elevados porcentajes: sobre una cuarta parte de la población. [...] El seiscientos es una época trágica. [...] El Barroco parte de una conciencia del mal, del dolor" (Maravall 1975: 309, 310). Había, pues, un sentimiento generalizado de que la vida del hombre en la tierra es prácticamente nada. Uno de los emblemas más conocidos de Juan de Borja, en su libro Empresas morales, justo tenía como mote Hominem te esse cogita, "recuerda que eres hombre", recuerda que eres finito, que tu vida sobre la Tierra es prácticamente nada comparada con la eternidad.

En su libro Era melancólica. Figuras del imaginario barroco, Fernando de la Flor recupera un frontispicio anónimo del siglo XVII, en el que aparece una cruz con el título "caminos del (sic) nada", la cruz está dividida en cuatro secciones en su forma horizontal, y en siete en su forma vertical. Cada una de las secciones tiene un verso inscrito: "No desees nada - No pidas nada - No busques nada - No quieras nada". Los otros son poco visibles, pero nos dan una idea del pesimismo que impregnaba el imaginario de la época.

Si revisamos la literatura del Siglo de Oro, la conciencia de muerte atraviesa a todos los grandes autores de la época. Muerte y melancolía definen a los grandes personajes. En la tradición protestante pensemos por ejemplo en Hamlet, y dentro de la tradición católica en don Quijote de Cervantes, quien, por cierto, no solo asume el apodo "el Caballero de la Triste figura", sino que al final del segundo libro termina muriendo de melancolía.5 De Baltasar Gracián voy a citar un solo fragmento de El Criticón (1998), donde aparece justo la conciencia de la muerte:

No es otro el vivir que un ir cada día muriendo (Cr. III’a, 11).

Mientras que Francisco de Quevedo escribe en el poema El escarmiento (1990):

5 Hay que recordar que, en la segunda parte de Don Quijote de la Mancha, capítulo LIX "Donde se cuenta del extraordinario suceso, que se puede tener por aventura, que le sucedió a don Quijote”, hay una escena emblemática: están don Quijote y Sancho en medio de la oscuridad, a orillas de un camino, después de haber sido atropellados por una manada de toros. Es una de las primeras veces donde se asoma el despertar trágico. "Come, Sancho amigo — dijo don Quijote-: sustenta la vida, que más que a mí te importa, y déjame morir a mí a manos de mis pensamientos y a fuerzas de mis desgracias. Yo, Sancho, nací para vivir muriendo y tú para morir comiendo" (Cervantes 2004: 996). 
No hagas de otro caso,

pues se huye la vida paso a paso;

y en mentidos placeres

muriendo naces, y viviendo mueres (vv. 119-122).

Por su parte, la analogía que hace Segismundo entre la fugacidad de la vida y el sueño en La vida es sueño, de Calderón de la Barca, es ampliamente conocida, por lo que no la voy a recuperar aquí. Pero sí otro fragmento de Quevedo, quien en imitación a Séneca escribe un poema llamado Morirás:

... Morirás. Desde que nací lo sé, por eso lo espero y no lo temo. Morirás. No dices bien: di que acabaré de morir y acertarás, pues con la vida empecé la muerte. Morirás. Me dices lo que sé y callas lo que no sé, que es el cuándo. Morirás (2008: 3, 4).

El triunfo de la muerte sobre la vida es pues, uno de los tópicos del barroco que persistirá hasta bien entrado el siglo XVIII ( $c f$. González 2003: 137) todavía en el barroco hispanoamericano, en el Políptico de la muerte ${ }^{6}$ aparece uno de los poemas más representativos de la cultura del barroco, que acompaña a una serie de elementos propios de la iconografía de la época:

Relox es la vida humana

(hombre mortal), y te avisa,

Que tu volante va aprisa,

Y muere al dar campana

Hoz, le sirve de puntero:

Antropos es reloxero:

Cloto el compaz encamina

Y la rueda catarina,

Ya llega al diente postrero.

Toda la muerte severa

Arruina, tala y destruye:

Nada de sus manos huye,

Porque todo es fuerza muera:

6 Obra anónima del periodo virreinal, se encuentra en el Museo Nacional del Virreinato, Tepotzotlán. En su texto: "Representación de la muerte en el arte colonial”, Gonzalo Obregón hace un seguimiento al concepto plástico de la muerte en la tradición hispanoamericana, los rasgos que lo conectan con el barroco europeo, etc. Su trabajo se puede consultar en Artes de México, "Miccaihuitl: el culto a la muerte", núm. 145, México, 1971. 
Oh naturaleza fiera!

Oh pensión dura, Oh heredad!

Relox, que en velocidad

Excedes a el mismo viento,

Y en el tiempo de un momento

Das paso a la eternidad.7

En su libro Vida, aventuras y muerte de don Juan, Giovanni Macchia señala que don Juan representa a la tierra sin cielo, a la tierra y a sus dóciles criaturas (cf. 1998: 14). El don Juan barroco, como sabemos, no es un seductor, y, a diferencia de otros donjuanes, este no guarda memoria de las mujeres con las que ha estado. Nunca las recuerda, ni guarda nada de ellas. Este don Juan parece ser la máxima expresión del amor entendido como carne. A diferencia de otros sacrílegos y ateos que aparecerán en la literatura de finales del siglo XVII y sobre todo en el XVIII, el don Juan barroco es totalmente vitalista, e inevitablemente sexual. Don Juan nace, decíamos, como la "protesta más violenta contra el culto a la muerte. [...] En la simbología amorosa representa la más fuerte oleada antipetrarquista que haya conocido la literatura" (Macchia 1998: 13).

Recordemos que el público de los Siglos de Oro, que asistía a las representaciones en los corrales, era, en su mayoría, el pueblo analfabeto, que poco podía esperar de su vida en la Tierra. ${ }^{8}$ Ellos, víctimas de las grandes pestes y la pobreza, estaban muy familiarizados con las vanitas. La conciencia de muerte pesaba sobre ellos. Por otro lado, los cambios que supuso la Contrarreforma afianzaron entre la población el sentimiento de la nada, el pecado y la muerte.

7 Véase la reproducción a color del cuadro en Andrea Montiel López, "El Políptico de la muerte: un compendio para el bien vivir en la Nueva España del siglo XviII", Vita Brevis. Revista electrónica de estudios de la muerte: Ideas de la muerte en México, II, núm. 4 año 3 (2014) enero-junio, en <https://mediateca.inah.gob.mx/repositorio/ islandora/object/articulo:14811> (consultado por última vez el 9 de marzo de 2020).

8 En la 'Introducción' a la antología El mito de don Juan, Carmen Becerra detalla cómo los patios y los edificios donde se representaban las obras más populares del siglo XviI el público se distribuía por estratos sociales: "La zona más barata daba acceso a una zona libre para los espectadores a pie; para los de más categoría social que podían pagar una entrada más cara, se destinaban gradas y bancos; para los nobles se reservaban los aposentos, semejantes a los palcos modernos, ubicados sobre los callejones laterales. El escenario se situaba al fondo, elevado y cubierto por el techo" (2019: XVI). 
No hay que olvidar que la Contrarreforma puede verse también como una cultura de la sospecha. Todo mundo podía ser sospechoso y estar bajo la mira de la Santa Inquisición. "La religión es ahora la norma de vida, guía la conducta y la moral civil de las gentes. El miedo al contagio de la herejía provoca que los españoles se encierren en sí mismos [...]. El Santo Oficio se erige en la salvaguarda de la doctrina (Índice de libros prohibidos)" (Becerra 2019: XIII). El problema era que la religión condenaba, dirigía eternas e inútiles invitaciones al arrepentimiento, pero no garantizaba, en términos reales, aquello que los hombres tendrían después de morir. Al público que participaba de la puesta en escena de una obra como El burlador de Sevilla, no le quedaba otra cosa más que disfrutar del goce de don Juan. Además, en su mayoría, nunca podrían acceder al tipo de placeres que escenifica ese hombre que parece casi un semidiós griego, que siempre sale victorioso de cada encuentro, que puede contra todos, que destruye y queda impune; para el que parece no haber institución terrenal que pueda castigarlo. El público gozaba, en una especie de catarsis, incluso cuando el personaje mataba, porque en el fondo el público sabía que no participaría de la condena del pecador, pero sí del disfrute.

El don Juan barroco nos recuerda pues a ese Nietzsche del siglo XIX gritando "permaneced fieles a la Tierra"; totalmente arraigado al mundo. Al don Juan barroco no le inquietan las promesas o los castigos del más allá. Su siempre "tan largo me lo fías" aparece como un escudo contra todo lo que no pertenece a la Tierra. Don Juan, a diferencia de otras figuras que marcan el inicio de la Modernidad, como Fausto, no necesita del diablo para obtener lo que desea. Hay que recordar que el Fausto barroco, además de pedirle a Mefistófeles una serie de deseos relacionados con la magia y el conocimiento, en algún momento le plantea la posibilidad de enamorarse, de compartir su vida con alguien; Mefistófeles reacciona inmediatamente a eso, y para disuadir a Fausto, le otorga un harén de mujeres hermosas con las que el mago realizará orgías. Obviamente estas mujeres en realidad son demonios. 9

Dentro de la tradición española del Siglo de Oro, también existe el tema del pacto con el diablo. Solo que a diferencia de lo que ocurre en la tradición fáustica protestante, donde el pacto siempre tiene un objeto u objetivo

9 La versión que se menciona aquí es la del siglo XVI, editada por Johan Spies. Cf. Anónimo, Historia del doctor Johann Fausto, trad. Juan José del Solar. Barcelona, Siruela, 2004. 
trascendental, el pacto con el diablo en la tradición española está marcada por la concupiscentia carnis, es decir, que siempre tiene un fin sexual. ${ }^{10}$

Frente a los personajes pactantes con el diablo en la literatura del Siglo de Oro, don Juan aparece como una burla, porque él no necesita del diablo para gozar de los placeres terrenales. En el teatro de los Siglos de Oro hay una serie de personajes que pactan con el demonio para poder gozar de la mujer que desean. Una obra anterior a El burlador de Sevilla, y que trata sobre el mencionado tema es precisamente El esclavo del demonio, de Mira de Amescua, escrito probablemente en 1612 o un poco antes, es una de las primeras obras del teatro español en la que se explora el tema del pacto con el diablo. El protagonista, don Gil, vende su alma para poder gozar de Leonor, hermana de Lisarda (a quien ya había engañado anteriormente).

Por gozar de ti, Leonor

daré el alma (El esclavo del demonio, vv. 1426-1427)

Otra obra, al parecer anterior pero que se representó hasta 1629, La gran columna fogosa, San Basilio Magno, de Lope de Vega, narra la historia de un sirviente llamado Proterio que se enamora perdidamente de su señora, Antonia, una dama que no solo posee una buena posición social, sino que además ha decidido entregarse a la vida conventual. La desesperación de Proterio lo lleva a pactar con el demonio.

Casi en los mismos años en los que sale la primera edición que se conoce de El burlador de Sevilla (1630), atribuida a Tirso de Molina, circuló también una obra de Calderón de la Barca que aborda el tema del pacto con el diablo: El mágico prodigioso (1637). Su protagonista, Cipriano, también vende su alma al demonio para poder seducir a Justina:

Ya rendido y ya sujeto

A penar y padecer,

Por gozar a esta mujer

Diera el alma (vv. 1196-1199)

10 Probablemente la única excepción sea Irene, la protagonista de Las cadenas del demonio (1630), obra atribuida a Calderón de la Barca: en ella, Irene pacta con el diablo a cambio de obtener su libertad, pues desde pequeña ha permanecido encerrada en una torre, donde desde la ventana mira pasar un mundo que nunca ha experimentado. El pacto de Irene con el diablo no tiene un fin material ni está relacionado con la concupiscentia carnis, como en las otras obras de la época. 
Como se puede ver, el elemento que une a estas tres obras es que el pacto con el diablo siempre está relacionado con la lujuria. Los pactantes con el diablo, dentro de la tradición española, no persiguen un fin trascendental como el Fausto de la tradición protestante. El pactum cum diabolo contrahatur tiene como motivo la concupiscentia carnis. La atracción de una mujer, en principio imposible, es lo que lleva a los personajes como don Gil, Proterio o Cipriano a buscar la intervención del demonio. De pronto ellos se dan cuenta de su impotencia: por sí mismos no pueden obtener a la mujer que desean. Por sí mismos no pueden saciar sus deseos, aunque estos sean deseos primarios, pues no pretenden un conocimiento absoluto, ni secretos sobre la naturaleza o la divinidad. Sus deseos están atados a lo terrenal; permanecen fieles a la Tierra, solo que, a diferencia de don Juan, estos no pueden llevar a cabo sus empresas por sí mismos. De hecho, son una especie de contraejemplos de don Juan. Proterio es un esclavo, es consciente de que su deseo por Antonia no va a prosperar, no puede seducirla, ella ni siquiera lo mira. Don Gil, por su parte, quiere gozar de la hermana de Lisarda. Ella, al igual que Antonia ha decidido entregar su vida a Dios. La diferencia es que don Gil es un fraile converso, que por la tentación del demonio deshonra a Lisarda, y también quiere poseer a Leonor, quien huye de todo intento de seducción. La única salida que encuentran estos seductores fallidos es acudir al demonio. Vemos, pues, que estos personajes, tan hijos de la Contrarreforma, lo único que quieren es gozar de la carne; ninguno aspira a nada trascendente; en esto son muy parecidos a don Juan. No tiene sentido hablar de otra vida si no se ha podido gozar la que se tiene.

Desde sus orígenes en el teatro de los Siglos de Oro, don Juan ha sido "un símbolo del placer carnal” (Méndez 2000: 133); cuando alguien pronuncia su nombre, inevitablemente pensamos en la voluptas carnis. Mucho antes de que se introdujera la conversión, el arrepentimiento y la seducción (siglo XIX) en la historia de don Juan, uno de los pilares que sostenía el discurso era el instinto sexual escenificado por el personaje. ¿Cuál era el otro pilar? La muerte.

En Vida, aventuras y muerte de don Juan, Giovanni Macchia nos dice que en el siglo XVII don Juan nace del gusto por la muerte ( $c f$. 1998: 13). La conciencia de muerte, tan presente en el mundo barroco, fue sustancial para la aparición de un personaje en el que aparecen hermanados el placer y la muerte. "Sexo y muerte. Eros y Thánatos, manifiestan su unidad en la figura de don Juan” (Méndez 200o: 133). 
Sin importar que la obra sea de Tirso de Molina o de Andrés de Claramonte, lo que se debe tener presente es que la primera versión de don Juan, la del siglo XVII, deja claro que este personaje se "identifica con el gozo temporal en el presente y escapa a su otro rostro, la muerte" (Méndez 2000: 133). De ahí el acierto de ese autor del siglo XVII al ponerle como título El burlador de Sevilla y el Convidado de piedra. El burlador encarna la imagen de la sexualidad, y el convidado "la muerte".

Ahora bien, sin el convidado de piedra el mito de don Juan pierde uno de sus pilares fundamentales. De hecho, es el problema que presentan las versiones de don Juan a partir de finales del siglo xix. En un mundo donde se ha decretado la muerte de Dios y el fin de los grandes relatos de la metafísica que habían atravesado a la cultura occidental, de pronto la historia de un hombre malvado, al que no le importa que su alma se condene con tal de disfrutar los placeres terrenales, adquiere otro sentido.

Desde su aparición en el siglo XVII, don Juan anuncia elementos del héroe trágico moderno; pero no a la manera de los griegos, sino de los héroes trágicos de fin de siglo. Sin pretenderlo muestra una conciencia nihilista. Es un personaje que lleva sus actos hasta las últimas consecuencias; la idea de que aparezca un emisario del más allá para ajusticiarlo termina redondeando el argumento. Y justamente esto es lo que se pierde a finales del siglo xIX: ya no hay convidado de piedra, ya no existe ese elemento que lo conecte con lo religioso. Sin embargo, surgen otro tipo de castigos que acabarán con la vida del don Juan tardomoderno: un infarto, la soledad, el hastío, o el suicidio.

Cuando en el siglo XVII, casi al final de El burlador de Sevilla y Convidado de piedra, o de sus variantes, Tan largo me lo fías, La venganza en el Sepulcro, aparecía la figura del vengador ofendido, en realidad no constituía un elemento nuevo. La literatura medieval, la tradición oral sobre todo, está llena de lugares (topoi) donde aparece la figura del muerto ofendido que regresa a vengarse, que aparece en una cena, o el día de las nupcias de su ofensor o asesino; fantasmas que acuden al festín con sus familiares, caballeros que ven cómo un séquito de demonios acude a su llamado; el convite con los muertos parece ser, pues, un motivo central en la literatura medieval europea. ${ }^{11}$

11 Agradezco al doctor José Manuel Pedrosa, quien amablemente me proporcionó el libro Tras las huellas de don Juan. Por el norte de África y la Grecia clásica, de Óscar Abénojar, así como su propio artículo "El mito de don Juan y el cuento tradicional de El cadáver ofendido (atu470a)", que han sido de gran ayuda para la escritura de este texto. 
En su libro Tras las huellas de don Juan. Por el norte de África y la Grecia clásica (2018), Óscar Abénojar documenta centenares de versiones del cuento de la calavera ofendida. En la mayoría de las versiones hay algo que persiste: un joven se burla de un cadáver y lo invita a cenar a su casa. En otras versiones, lo invita a su boda. En todas, el convidado acude a la hora acordada y se sienta en la mesa del anfitrión, causando gran miedo entre los otros convidados, o haciendo que el joven protagonista se vuelva presa del terror. En casi todas - nos dice Abénojar - cuando llega el momento de irse, el muerto le devuelve la invitación, pero ahora el convite tendrá lugar en el cementerio o en la iglesia. Hay que recordar que antes los cementerios se situaban en el atrio de las iglesias o dentro de ellas. En la escena final, el joven imprudente será objeto de un escarmiento por haberse burlado de los muertos (cf. 2018: 7, 8).

Existen varios estudios y monografías sobre los orígenes del mito de don Juan y sobre las diferencias y semejanzas que tienen sus personajes con los protagonistas de otras obras del Siglo de Oro. No voy a sintetizar sus contenidos, pero sí a mencionar Los orígenes poéticos de El burlador de Sevilla y Convidado de piedra (1908), de Víctor Said Armesto, que, aunque fue publicado a principios del siglo $\mathrm{Xx}$, sigue siendo imprescindible para los interesados en el tema, y también, de Francisco Márquez Villanueva, Orígenes y elaboración de "El burlador de Sevilla" (1996).

Lo que aquí me interesa son las formas de representación simbólica de la muerte que acompañan al primer don Juan. En principio, hay dos escenas fundamentales del convite; la primera, cuando la estatua de don Gonzalo acude a la cita, y la otra, cuando la estatua le regresa la invitación, abriendo un segundo convite, pero ahora en el cementerio. Eso anuncia que en el cierre de la obra la verdadera protagonista será la muerte.

En Los orígenes poéticos de El burlador de Sevilla y Convidado de piedra, Víctor Said Armesto ya señalaba que el eje de toda la leyenda de don Juan, el centro donde convergen todos los radios de ficción es el convidado de piedra ( $c f$. 1908: 96). Don Juan no existe sin la aparición de esa estatua, fantasma, diablo, que irrumpe al final de la obra para arrastrarlo a los infiernos. Pero tampoco existe sin la concupiscentia carnis. En El burlador de Sevilla y Convidado de piedra la muerte y el placer carnal se encuentran cara a cara. Son los grandes protagonistas que circundan y dan cuerpo a un personaje que salta de un escenario a otro "desafiando las leyes del honor y la obediencia que debe a sus superiores en el orden familiar y social, desafía además a Dios, alzándose como eje vector de su propia ley y orden” (Egido 1988: 37). 
Me gustaría recuperar un dato que nos proporciona Said Armesto sobre ciertas costumbres medievales en algunos pueblos de Galicia, porque de alguna forma da una idea de cómo una sociedad comprende y se relaciona con la muerte; el fragmento en cuestión parece ser del arqueólogo gallego Barreiro de W, publicado en Galicia Diplomática (31 de octubre de 1883, artículo “La fiesta de los difuntos"):

en el siglo XVI en Galicia, de un modo harto raro, escandaloso y único. Costumbres bárbaras aún en boga en 1586, hicieron surgir y establecer la famosa orgía anual del 2 de noviembre, dedicada por las familias a sus parientes muertos. En las iglesias y en los atrios se inhumaban los cadáveres. Dentro y fuera, pues, debía celebrarse el banquete en honor de los difuntos (1908: 101).

Probablemente la escena que vemos representada casi al final de El burlador de Sevilla, un hombre acudiendo a cenar a un cementerio, no era del todo rara, pues la costumbre de ir a comer a los cementerios formaba parte del imaginario de la época. Cabe señalar, que, desde sus orígenes, la historia de don Juan aparece acompañada de la tríada sexo-muerte-alimentos. A finales del siglo xx, Jean Rousset (1985) llamaba la atención sobre el Don Giovanni de Mozart, como una obra donde extrañamente se come mucho; se brinda y se bebe. Pero esto en realidad ya está presente en las primeras versiones de don Juan, El burlador de Sevilla, Tan largo me lo fías, etcétera.

Y es que el don Juan del siglo XVII encarna, de una forma muy particular, aquella sentencia que en el siglo XIX un filósofo como Nietzsche gritará con fuerza: "Permaneced fieles a la Tierra” (2009: 43). Don Juan pudo haber exclamado ¡Celebrad las delicias que nos ofrece la Tierra, con todas sus impurezas e imperfecciones! ¡Disfrutad de la belleza efímera, de la alegría y del dolor! Pues estas tienen sentido en la medida en que existe la muerte. Don Juan nunca añora la belleza absoluta, ni el conocimiento absoluto como Fausto. Don Juan se sabe finito, y como hombre finito desea los placeres terrenales. Sabe que la muerte nos acecha a cada instante.

Por último, pareciera que el carpe diem barroco encuentra su correlato en don Juan: hay que disfrutar de la carne antes de que envejezca. De alguna forma, don Juan absorbe también el sentimiento de fugacidad tan propio del barroco, lo asume y lo dota de otro sentido.

La vida es un breve instante en lo desconocido de la eternidad. Ese breve instante transcurre en un lugar donde las cosas nacen, perecen y se olvidan. 
Por eso hay que disfrutarlas, no importa que el disfrute sea momentáneo. No importa perder el alma por toda la eternidad si por un instante seremos felices y completos en la tierra. El don Juan barroco es, pues, una metáfora de la existencia estética. De haber podido, habría gritado igual que Nietzsche "Permaneced fieles a la Tierra", pero él no llega a la reflexión. Le falta la palabra, el buen discurso. Y es que el primer don Juan, como lo verá siglos más tarde Sören Kierkegaard, no puede "definir" la existencia estética, pero sí la escenifica, la encarna.

\section{Bibliografía}

ABENóJAR, Óscar (2018). Tras las huellas de don Juan, por el norte de África y la Grecia Clásica. Madrid, Mitáforas, 7.

ARIÈs, Philippe (1993). El hombre ante la muerte. Madrid, Taurus.

Becerra, Carmen (ed.) (2019). El mito de don Juan (Antología). Madrid, Biblioteca Castro.

Calderón de la Barca, Pedro (20oo). El mágico prodigioso, W. Wardropper (ed.). Madrid, Cátedra.

Cervantes Saavedra, Miguel de (2004). Don Quijote de la Mancha, ed. Francisco Rico. Madrid, Real Academia Española-Asociación de Academias de la Lengua Española.

De Borja, Juan (1981). Empresas morales, C. Bravo Villanante (ed.). Madrid, Fundación Universitaria Española.

De LA FloR, Fernando R. (2007). Era melancólica. Figuras del imaginario barroco. Barcelona, José J. de Olañeta editor-Ediciones UiB.

De LA FloR, Fernando R. (2002). Barroco. Representación e ideología en el mundo hispánico (1580-1680). Madrid, Cátedra.

De VegA, Lope (1964). La gran columna fogosa. San Basilio Magno, en O. C., Marcelino Menéndez Pelayo (ed.), tomo IX. Madrid, RAE.

Egido, Aurora (1988). "Sobre la demonología de los burladores (De Tirso a Zorrilla)", en Cuadernos de Teatro Clásico, núm. 2, Ministerio de Cultura: 37-63.

GonZÁLEz GARCíA, José M. (2003). "La cultura del barroco: figuras e ironías de la identidad", Revista Devenires, México, IV, núm. I: 117-154. Gracián, Baltazar (1998). El Criticón, Elena Cantarino (ed.). Madrid, Espasa.

Jouan Dias Angelo De Souza, Carla (2018). "Muerte y representación en la Edad Media: consideraciones sobre la imagen, la iconografía de la muerte y la influencia de la Peste Negra en el surgimiento de los temas macabros", De Medio Aevo, vol. 12, núm. 1: 239-258.

Macchia, Giovanni (1998). Vida, aventuras y muerte de don Juan. Madrid, Tecnos.

Maravall, José Antonio (1975). La cultura del barroco. Análisis de una estructura histórica. Barcelona, Ariel. 
Márquez Villanueva, Francisco (1996). Orígenes y elaboración de "El burlador de Sevilla”. Salamanca, Ediciones de la Universidad de Salamanca.

MÉndez, Sigmund (200o). El mito fáustico en el drama de Calderón. Reichenberg, Kassel.

Mira de Amescua, Antonio (1980). El esclavo del demonio, James A. Castañeda (ed.). Madrid, Castalia.

NiETzsche, Friedrich (2009). Así hablaba Zaratustra. México, Universidad Veracruzana.

Pedrosa, José Manuel (2007). "El mito de Don Juan y el cuento tradicional de El cadáver ofendido (atu47oa)”, en Hecho Teatral (Revista de teoría y práctica del teatro hispánico), núm. 7, Valladolid, Universitas Castellae.

Quevedo, Francisco de (1990). Poesía original completa, José Manuel Blecua (ed.). Barcelona, Planeta.

QuevEDo, Francisco de (2008). Remedios de cualquier fortuna (Traducción y glosa del De remediis fortuitorum), Juan Pablo Canala (ed.). Buenos Aires, Princeps.

Rousset, Jean (1985). El mito de don Juan, trad. Juan José Utrilla. México, Fondo de Cultura Económica.

SAID ARmeSto, Víctor (1908). La leyenda de don Juan: orígenes poéticos de "El burlador de Sevilla" y "Convidado de piedra”. Madrid, Espasa-Calpe.

SEBASTIÁn LÓPEZ, Santiago (1989). Contrarreforma y barroco: lecturas iconográficas e iconológicas. Madrid, Alianza.

VILLARI, Rosario (1991). El hombre barroco. Madrid, Alianza editorial.

\section{Leonarda Rivera}

Doctora en Filosofía por la UNAM. Profesora de asignatura en la Facultad de Filosofía y Letras de la misma institución. Realizó una estancia posdoctoral en el Centro de Estudios Literarios del Instituto de Investigaciones Filológicas de la UNAM. Forma parte del proyecto de investigación "Narrativas en transición: Filosofía, literatura y ciencias sociales hacia la construcción de un Estado democrático" (SI1/ PJI/2009-00307) de la Universidad Autónoma de Madrid. También participó en el proyecto DGAPA-PAPITT IN404016 "Crisis de la Escolástica, humanismo del Siglo de Oro español y su influencia en México”. Actualmente es miembro del Sistema Nacional de Creadores. 